\title{
Pharmacological strategies for the management of cancer pain in developing countries
}

\author{
Afekhide E. OMOTI, Caroline E. OMOTI
}

\begin{abstract}
${ }^{*}$
Pain associated with cancer is often under treated especially in the developing countries where there are problems of poor economy, poor purchasing power of the citizens, absence of effective national health insurance schemes, poor manpower, fake adulterated and expired drugs, poor drug storage conditions; adverse temperature conditions combined with poor power supply which may affect drug efficacy. There is also poor understanding of the physiopharmacology of cancer pain management by health care providers. Assessment of the severity of the pain by location, oncological type, as well as psychosocial, emotional and environmental factors are necessary. The pain often occurs from malignancy, from procedures done to diagnose, stage and treat the malignancy, and from the toxicities of therapy used in treating the cancer. The first priority of treatment is to control pain rapidly and completely, as judged by the patient. The second priority is to prevent recurrence of pain. Analgesic drugs are given 'by the ladder,' 'by the clock' and 'by the appropriate route' using the analgesic ladder guideline proposed by the World Health Organization (WHO). The pharmacological aspects of various drugs used in the management of cancer pain are discussed.
\end{abstract}

Keywords: Pain. Neoplasms. Analgesics.

\section{RESUMEN}

El dolor asociado al cáncer está a menudo infratratado, especialmente en países en vías de desarrollo con problemas de pobreza, poco poder de compra de los ciudadanos, ausencia de esquemas de seguridad social efectivos, poca mano de obra, medicamentos falsificados o adulterados o caducados, malas condiciones de conservación, temperaturas adversas combinadas con suministros eléctricos deficientes que pueden afectar la eficacia del os medicamentos. También hay un pobre conocimiento de la fisiofarmacología del manejo del dolor del cáncer por los profesionales del a salud. Se necesitan evaluaciones del a gravedad del dolor por la localización, tipo de cáncer, así como factores psicosociales, emocionales y ambientales. El dolor aparece a menudo por la malignidad, los procedimientos realizados para diagnosticar el estado y tratar la enfermedad, y por la toxicidad del tratamiento del cáncer. La primera prioridad del tratamiento es controlar el dolor rápida y completamente, en juicio del paciente. La segunda prioridad es prevenir la recurrencia del dolor. Los analgésicos deben usarse 'en escalones', 'en tiempo' y por la 'vía apropiada' utilizando la guía de escalones analgésicos del a Organización Mundial del a Salud (OMS). Se discuten los aspectos farmacológicos del as diversos medicamentos utilizados en el manejo del dolor de cáncer.

Palabras clave: Dolor. Neoplasias. Analgésicos.

\section{(English)}

\section{INTRODUCTION}

Pain is the main reason prompting patients to consult their physicians. ${ }^{1}$ Basically, there are two components of pain. ${ }^{2}$ The first component is the sensory input to the central nervous system that results in recognition of the sensation of pain. The second component is the reactive, subjective component. Acute pain has a very particular significance as a warning sign, enabling the physician to attempt a diagnosis. ${ }^{1,2}$ Such is not the case with chronic pain, especially that due to cancer. $^{2}$ The psychological and social aspects, particularly in chronic pain should not be ignored. ${ }^{1}$ Depression, anxiety, fear, mental isolation, other unrelieved symptoms and pain itself will all tend to exacerbate the total experience of pain. ${ }^{2}$ To relieve

\footnotetext{
Afekhide E. OMOTI. MB;BS, FWACS, FMC(OPH). Department of Ophthalmology, University of Benin Teaching Hospital, Benin City, Nigeria. Caroline E. OMOTI. MB;BS, FMC(Path). Department of Haematology, University of Benin Teaching Hospital, Benin City, Nigeria.
} 
the pain in cancer, all these factors must be taken into consideration.

Pain associated with cancer is of widespread concern. ${ }^{3}$ The pain often occurs from malignancy, from procedures done to diagnose, stage and treat the malignancy, and from the toxicities of therapy used in treating the cancer. ${ }^{4}$ Of people with cancer, $75 \%$ complain of some sort of pain. ${ }^{5}$ Surveys indicate that clinicians are frequently ill equipped to treat cancer pain and the outcomes achieved in clinical practice are often suboptimal., ${ }^{5,6}$ This is especially so in developing countries which are also plagued with the problems of poor economy, poor purchasing power of the citizens, absence of effective national health insurance schemes, poor manpower, fake adulterated and expired drugs, poor drug storage conditions; adverse temperature conditions combined with poor power supply which may affect drug efficacy. ${ }^{7-10}$ Poor drug policies and absence of many of the effective drugs in the essential drug list of many of these countries further makes them unavailable and expensive. The drug manufacturing firms are also located in the developed countries and drugs have to be imported into the developing countries further increasing their cost to the patients. ${ }^{7-10}$

\section{PHYSIOPHARMACOLOGICAL ASPECTS OF PAIN.}

Effective management requires an understanding of pain pathophysiology, the ability to identify and evaluate pain syndromes and familiarity with proven therapeutic strategies. ${ }^{5}$ Besson gives a brief description of the complexity of the pain circuit as follows. ${ }^{11}$ Peripheral nociceptive messages are conveyed by a mosaic of unmyelinated free fibres distributed throughout cutaneous, muscular and articular tissue, and within the visceral walls. They are then transmitted via various nerve endings (polymodal nociceptors) by small diameter A delta and $C$ fibres, which are activated by mechanical, thermal and chemical stimuli. It is nevertheless difficult to ascertain whether these small diameter fibres are involved only in nociception (specific nociceptors) or whether pain causes an excessive activation of these receptors, which under normal conditions have a role in the reflex that regulates various functions (nonspecific nociceptors). Numerous chemical substances play a part in generating nociceptive impulses (e.g. histamine, serotonin, prostaglandins). Furthermore, the role of neuropeptides, such as calcitonin gene-related peptide and particularly substance $P$, has been clearly demonstrated in the activation of early neurogenic inflammation. Other substances, such as bradykinin and cytokines, are involved in prolonging the sensation of pain. Nerve growth factor also prolongs the sensation of pain by increasing the cellular excitability of nociceptors and promoting the action of the sympathetic nervous system, which has a major role in controlling pain. The very great diversity of all these interacting substances makes the pharmacological treatment of pain extremely complex. Nevertheless, new therapeutic advances are providing interesting approaches, particularly the development of specific inhibitors of cyclo-oxygenase 2 (COX 2), which is produced by the inflammatory process. Such inhibitors would preserve $\operatorname{COX} 1$, which is both constitutive and physiological, and thereby provide improved tolerability compared with currently used NSAIDs, which act upon both COX pathways. A major focus of research relating to new analgesics is the development of synthetic antagonists of bradykinin, substance $\mathrm{P}$ and $\mathrm{N}$-methyl-D-aspartate receptors. An improved understanding of anatomical and electrophysiological processes has led to the discovery of new ascending pathways that transmit nociceptive messages to the reticular formation, the hypothalamus, and the amygdala, as well as to certain areas of the cortex. As a result the notion of one single pain centre is no longer valid. This idea is further reinforced by the knowledge that, at different stages of the pain pathway, different control systems constantly modulate the transmission of nociceptive information.

\section{GUIDELINES FOR TREATMENT OF CANCER PAIN}

The nature and severity of the pain should be carefully evaluated using the history and physical examination. ${ }^{12}$ Assessment of the severity of the pain by location, oncological type, as well as psychosocial, emotional and environmental factors are necessary. ${ }^{4,12}$ The severity of pain can be quantified by several pain scales. A four-point verbal Likert scale, ${ }^{13}$ or the Visual analogue scale $;^{14,15}$ with word descriptors ranging from no pain (0) to excruciating pain (10) can be used. A similar scale can be used with children and with patients who cannot speak; this scale depicts five faces ranging from smiling (no pain) to crying (maximum pain). ${ }^{15}$ It is however possible to develop tools for pain assessment that are appropriate for all cultures. All such scales are based on the concept of counting, which is universal.

The first priority of treatment is to control pain rapidly and completely, as judged by the patient. The second priority is to prevent recurrence of pain. Analgesic drugs are given 'by the ladder,' 'by the clock' and 'by the appropriate route'. The analgesic ladder guideline proposed by the World Health Organization (WHO) has been shown to be effective in controlling cancer pain in about $80 \%$ of patients, but the remaining $20 \%$ still experience pain. ${ }^{16}$ The ladder approach is based on the premise that health care professionals should learn how to use a few drugs well. The WHO Ladder is a 3-step approach. The first step involves the use of a non-opioid analgesic alone. The second step involves the addition of a weak opioid when pain is inadequately treated by a non-opioid analgesic alone. The third step is the use of a powerful opioid analgesic.

The administration of analgesic medication should be a regular schedule, around the clock, with additional doses for breakthrough pain when necessary. ${ }^{12}$ It is easier to prevent pain from occurring than to treat it once it has recurred. Providing sustained analgesia is an important 
aspect of therapy and regular administration of doses maintains a constant level of drug in the body and helps prevent recurrence of pain. ${ }^{17}$ The ideal treatment for persistent pain is a long-acting opioid administered around the clock to prevent baseline pain, with the use of short-acting opioids as supplemental agents for breakthrough pain. ${ }^{17}$ Controlled release formulations can lessen the inconvenience associated with around-the-clock administration of short-acting opioids. Sustained analgesia can also be achieved with transdermal fentanyl, which combines a strong opioid with a 72hour release profile and the benefits of a parenteral route, avoiding first-pass metabolism. ${ }^{17}$ If the oral route fails, transdermal or rectal route should be considered. $^{12}$ When parenteral administration is necessary, the intravenous or subcutaneous route can be used according to circumstances. Intramuscular administration of opioids is not recommended. $^{12}$

Several strategies have been used to manage refractory cancer pain and opioid toxicity. $6,16,18$ Switching opioids, alternative routes of opioid administration, optimizing adjuvants and invasive procedures are proposed treatment modalities. ${ }^{16}$ Non-invasive interventions include the use of adjuvant analgesics, psychological therapies and psychiatric techniques. ${ }^{6,18}$ Invasive interventions include the use of intraspinal opioids, neural blockade and neuroablative techniques. ${ }^{6,18}$ Sedation is an option at the end of life for the management of pain that is refractory to other interventions. 5,6,18 Patients with refractory pain should have access to specialists in pain management or palliative medicine to address the difficult problems. ${ }^{18}$ Such specialists are usually in short supply in developing countries.

\section{BARRIERS TO EFFECTIVE MANAGEMENT OF CANCER PAIN.}

There are several barriers to effective pain management in cancer patients. ${ }^{5,19,20,21}$ These may be classified into barriers related to the health care professionals, barriers related to the patient, and barriers related to the health care system. Barriers related to health care professionals include: Insufficient knowledge of pain management, poor assessment of pain, concern about regulation of opioids, fear of patient addiction and tolerance to opioids and side effects of the analgesics. Unfounded fear of addiction may lead caregivers to administer opioids as a last resort. As a result, many patients may not receive potent analgesics required to relieve severe cancer pain. In the case of children, misunderstanding of the pharmacokinetics of opioids can result in prescribing analgesics in inadequate doses, at inappropriate intervals and by unnecessarily painful or less effective routes.

Barriers related to patients include reluctance to report pain, reluctance to take analgesics for various reasons, concern about distracting the physicians from treating the underlying disease, fear of being thought of as a drug addict, concern about side effects and tolerance to the drugs, and poor drug compliance. Problems related to the health care system include restrictive regulation of controlled drugs, availability or accessability to the patient, high cost of drugs, low priority given to cancer pain treatment and inadequate or no reimbursement for these drugs.

State and local laws may restrict the medical use of opioids to relieve cancer pain, and third-party payers may not reimburse for non-invasive pain control treatments. Thus, clinicians should work with regulators, pharmacists, state cancer pain initiatives, or other groups to eliminate these health care system barriers to effective pain management. Effective pain management is best achieved by a team approach involving patients, their families and health care providers.

\section{MEDICAL MANAGEMENT OF CANCER PAIN}

There are four basic approaches to cancer pain control: modify the source of pain, alter central perception of pain, modulate transmission of pain to the central nervous system (CNS) and block transmission of pain to the CNS. ${ }^{22}$

The management of cancer pain requires familiarity with a range of therapeutic strategies, including antineoplastic therapies, analgesic pharmacotherapy, and anaesthetic, neurosurgical, psychological and rehabilitative techniques. ${ }^{23}$ The drugs currently used to treat cancer pain can be classified basically into 4 groups. ${ }^{24}$ 1) Nonsteroidal anti-inflammatory drugs (NSAIDS) with emphasis on cyclooxygenase-2 (COX-2) inhibitors; 2) Opioid analgesics, with specific emphasis on methadone and its newly recognized value in cancer pain; 3 ) Ketamine, an antagonist at $\mathrm{N}$-methyl d-aspartate (NMDA) receptors; and 4) Biphosphonates, used for pain resulting from bone metastasis. Opioid analgesics are widely acknowledged as the most important drugs for the treatment of chronic cancer pain. ${ }^{25}$ However, they may produce new symptoms or exacerbate pre-existing symptoms. An adjuvant drug should meet one of the following criteria: 1 . to increase the analgesic effect of opioids; 2 . to decrease their toxicity; 3 . to improve other symptoms associated with terminal cancer. Many drugs such as NSAIDS, tricyclic antidepressants, corticosteroids, benzodiazepines, amphetamines, antiemetics, oral local anaesthetics, bisphosphonates, anticonvulsants and antiarrhythmic drugs have been suggested to have adjuvant analgesic effect. ${ }^{1,4,25,26}$

\section{Non-steroidal anti-inflammatory drugs}

NSAIDs are widely used to treat cancer pain and are frequently combined with opioids in combination preparations for this purpose. ${ }^{27}$ NSAIDs act by inhibiting the enzymes that synthesize prostaglandin's; cyclooxygenases (COX-1, COX-2) and also act upon lipo-oxygenases. ${ }^{1}$ Their efficacy is interesting, although somewhat limited by both their ceiling effect and the frequent adverse gastrointestinal reactions they produce. ${ }^{1}$ Specific inhibitors of COX-2 could well reduce the risk of 
adverse reactions. ${ }^{1}$ NSAIDs are reported to synergistically potentiate opioid effects via the activation of the periaqueductal grey of the midbrain. ${ }^{28}$ The analgesic action of opioids would also be potentiated by the activation of alpha-2adrenoceptors of the spinal cord. ${ }^{28}$ Several studies have shown that NSAIDs appear to be more effective than placebo for cancer pain; clear evidence to support superior safety or efficacy of one NSAID compared with another is lacking; and trials of combinations of an NSAID with an opioids have disclosed either no significant difference, or at most a slight but statistically significant advantage compared with either single entity. ${ }^{27,29,30}$ Recommended supramaximal single doses of three NSAIDs produced comparable changes in pain scores, which indicates a ceiling analgesic effect, but the incidence of side effects showed a trend to increase with dose, without a ceiling effect, and to increase with multiple doses. ${ }^{30}$ These findings question whether the traditional WHO second analgesic step is warranted. ${ }^{30}$

\section{OPIOID ANALGESICS}

Opioid analgesics are widely acknowledged as the most important drugs for the treatment of chronic cancer pain. ${ }^{25}$ There are several classifications of these drugs. ${ }^{1,31}$ Firstly weak opioids (such as codeine) and strong opioids (such as morphine) are differentiated. Secondly, a distinction is made between pure agonists (such as morphine), partial agonists (such as buprenorphine), agonistantagonists (such as nalbuphine) and antagonists (such as naloxone). Finally, agents are distinguished on the basis of their chemical structure (synthetic, semi-synthetic or natural derivatives). These molecules act upon different receptors (mu, delta, kappa, sigma) and, although peripheral mechanisms have been described, their activity occurs mainly at spinal and supraspinal levels. They provide a potent analgesic effect but are also responsible for various adverse effectsnausea, vomiting, sedation, constipation and respiratory depression-which seriously limit their use. As long as the indication is appropriate, these drugs should not be withheld because of fear of dependence or abuse.

\section{Morphine and methadone}

Morphine is a pure alkaloid, which has been used to relieve pain for many years, since it was isolated from opium poppy in 1803 by Serturner. ${ }^{15}$ Oral morphine in either immediate release or sustained release form remains the analgesic of choice for moderate or severe cancer pain. ${ }^{32}$ Methadone is a synthetic opioid, with mu and delta receptor activity, associated with the capacity to inhibit N-methyl-Daspartate receptors. ${ }^{33}$ It is an alternative to morphine which has been proposed in the control of opioid-induced toxicity. ${ }^{33}$ Variable results have been found in prospective studies that compare morphine with methadone. ${ }^{34,35}$ In one study, methadone did not produce superior analgesic efficiency or overall tolerability at 4 weeks compared with morphine as a first-line strong opioid for the treatment of cancer pain. ${ }^{34}$ In another study, differences in pain intensity were found. ${ }^{35}$ Patients treated with methadone reported values of opioid escalation indices significantly less than those observed in patients treated with morphine. Furthermore, much more patients in the methadone group maintained the same initial dosage until death. ${ }^{35}$

Opioid switching is often used to improve the opioid response in cancer patients experiencing poor analgesia or adverse effects. ${ }^{36}$ Rapid substitution of morphine with methadone using an initial fixed ratio of $5: 1$ has been reported to be a safe and effective method for improving the balance between analgesia and adverse effects in cancer patients with poor morphine response. ${ }^{36,37}$ However, one study conducted to determine the equianalgesic dose ratio reported that dose ratios ranged from 2.5:1 to $14.3: 1$ (median, 7.75:1), indicating that dose ratios may be much higher than that suggested by published equianalgesic tables. ${ }^{13}$

\section{BREAKTHROUGH (EPISODIC) PAIN}

Breakthrough pain is a transient increase in pain intensity over background pain. ${ }^{38}$ It is a common and distinct component of cancer pain that can have a negative impact for both the patient and carers' quality of life. Breakthrough pain is usually related to background pain and is typically of rapid onset, severe in intensity, and generally self-limiting with an average duration of 30 minutes. At present the current approach to managing breakthrough pain is using supplemental analgesia (also known as rescue medication) at a dose proportional to the total around-the-clock (ATC) opioid dose. ${ }^{38}$

Breakthrough pain is usually treated with shortacting oral opioids, most of which provide some relief after 15-20 minutes, with peak effects after 3045 minutes. $^{39}$ Oral transmucosal fentanyl citrate (OTFC), a unique formulation of the opioids fentanyl, has been shown to provide meaningful pain relief within 5 minutes in patients following surgery. ${ }^{39}$ Several studies have shown OTFC to be an effective treatment for breakthrough pain. ${ }^{38-41}$ When compared to placebo and morphine, users of OTFC gave lower pain intensity scores and higher pain relief scores at all time points. ${ }^{38}$ OTFC is a potent synthetic mu-agonist embedded in a sweetened matrix that dissolves in the mouth. ${ }^{40}$ In a study designed to determine the long term safety of OTFC, ${ }^{41}$ it was found that patients averaged 2.9 breakthrough pain episodes per day. About $92 \%$ of the episodes were successfully treated with OTFC and there was no trend towards decreased effectiveness over time. Common adverse events associated with OTFC were somnolence $(9 \%)$, constipation (8\%), nausea (8\%), dizziness (8\%) and vomiting (5\%). There were no reports of abuse and no concerns about safety of the drug raised by patients or families. ${ }^{41}$

\section{Buprenorphine}

Buprenorphine is a potent opioids analgesic that is available in sublingual, parenteral and in transdermal delivery systems. ${ }^{42}$ Transdermal 
buprenorphine is available in Europe for the treatment of moderate to severe chronic cancer pain at doses of $35,52.5$ and 70 microg/ $/{ }^{42,43}$ It has been found to be effective and well tolerated when used for the long-term treatment of chronic cancer pain. ${ }^{42,43}$ Patients on buprenorphine transdermal delivery system showed improved duration of sleep and reduced need for additional oral analgesics. ${ }^{42}$ The most common systemic adverse drug reactions were nausea $(9.2 \%)$, dizziness $(4.6 \%)$, vomiting $(4.2 \%)$, constipation $(3.8 \%)$, and tiredness $(2.9 \%)$, whereas the most common local adverse reactions were erythema (12.1\%), pruritus $(10.5 \%)$ and exanthema $(8.8 \%)$.

\section{Tramadol}

The limitations of opioids has motivated continuous research aimed at discovering drugs that can provide maximum pain relief but with improved tolerability. ${ }^{44}$ Tramadol has been shown to be effective in treating cancer pain and was better tolerated than buprenorphine. ${ }^{44}$ Tramadol is a synthetic 4-phenyl-piperidine analogue of codeine. ${ }^{45}$ Tramadol, a centrally acting analgesic, consists of two enantiomers, both of which contribute to analgesic activity via different mechanisms. (+) Tramadol and the metabolite (+) -O- desmethyltramadol (M1) are agonists of the mu opioid receptor. ${ }^{45,46,47}(+)$ Tramadol also stimulates presynapticrelease of serotonin and inhibits serotonin reuptake whereas (-) tramadol inhibits norepinephrine reuptake. Thus tramadol enhances inhibitory effects on pain transmission both by opioid and monoaminergic mechanisms. The complementary and synergistic actions of the two enantiomers improve the analgesic efficacy and tolerability profile of the racemate. ${ }^{46}$ Tramadol is available as drops, capsules and sustained-release formulations for oral use, suppositories for rectal use and solution for intramuscular, intravenous and subcutaneous injection. ${ }^{47}$

\section{Others}

Bromptons mixtures are occasionally used in terminal cancer. Cocaine was added to Bromptons mixtures (morphine or heroin + cocaine in an alcohol vehicle) to counteract the sedation from the opioids. Cocaine may be useful as a local anaesthetic in patients with head and neck cancer, when absorbed through mucuous membrane rather than swallowed.

Current research points to promising results identifying the N-methyl D-aspartate (NMDA) nonopioid receptor as a likely component of neuropathic pain. ${ }^{48}$ NMDA antagonists (eg dextromethorphan) are being studied for pain. Drugs such as gabapentin, the mechanism of action of which is not well known have found favour within the clinical community for their analgesic properties and good tolerability. ${ }^{48}$ Drugs such as cannabinoids, although currently applicable for patients with anorexia, nausea and or vomiting, may offer benefits to patients experiencing pain. Other opportunities exist with such compounds as alpha-2-adrenergic agonists, nicotine, lidocaine and ketamine. ${ }^{48}$ There is interest in the co-administration of opioids that act on different receptors. For instance, oxycodone appears to be a kappa opioids receptor agonist and may offer enhanced analgesia when combined with morphine. $^{48}$

\section{CONCLUSION}

Cancer pain management may be a difficult task in developing countries but a good understanding of the physiopharmacology, emotional and psychosocial aspects of cancer pain, adequate assessment of pain severity, and the application of the WHO analgesic ladder will be effective in most cases.

\section{References}

1. Brasseur L. Review of current pharmacologic treatment of pain. Drugs 1997; 53 Suppl 2:10-7.

2. Bressler L. Pain management in cancer patients. (1997). http://www.uic.edu/classes/pmpr/pmpr652/final/bressler/painmang.hmtl\#1

3. Carr DB, Goudas LC, Balk EM, Bloch R, loannidis JP, Lau J. Evidence report on the treatment of pain in cancer patients. J Natl Cancer Inst Monogr 2004; (32): 23-31.

4. Caimi $P$, Cymet TC. As if the cancer wasn't enough: understanding and treating the pain that comes with cancer. Compr Ther 2006; 32(3): 176-81.

5. Cherny NI, Portenoy RK. The management of cancer pain. CA Cancer J Clin 1994; 44(5): 263-303.

6. Cherny NI, Portenoy RK. Cancer pain management. Current strategy. Cancer 1993; 72(11 Suppl): 3393-415.

7. Omoti AE, Waziri-Erameh MJM. Compliance with medical therapy in patients with primary open angle glaucoma. Journal of Medicine and Biomedical Research 2003; 2(1):46-53.

8. Omoti AE, Ukponmwan CU. Compliance with new drugs in glaucoma therapy in Benin City, Nigeria. Seguimiento Farmacoterapeutico 2005; 3(3): 135-43.

9. Amoni SS. Changes of glaucoma in Africa. Nigerian Journal of Ophthalmology 1997; 5:56-9.

10. Omoti CE, Agada LO. Compliance with chemotherapy in adult leukaemia patients in Benin City, Nigeria. Seguimiento Farmacoterapeutico 2005; 3(1): 1-9.

11. Besson JM. The complexity of physiopharmacologic aspects of pain. Drugs 1997; 53 Suppl 2: 1-9.

12. The management of chronic pain in patients with breast cancer. The Steering Committee on Clinical Practice Guidelines for the Care and Treatment of Breast Cancer. Canadian Society of Palliative Care Physicians. Canadian Association of Radiation Oncologists. CMAJ 1998; 158 Suppl 3: S71-81.

13. Ripamonti C, Groff L, Brunelli C, Polastri D, Stavrakis A, De Conno F. Switching from morphine to oral methadone in treating cancer pain: what is the equianalgesic dose ratio? J Clin Oncol 1998; 16(10): 3216-21. 
14. Chiarini $\mathrm{L}$, Stacca $\mathrm{R}$, Bertoldi $\mathrm{C}$ et al. Mnangement of facial pain resulting from cancer in oral and maxillofacial surgery. Minerva Stomatol 1997; 46(1-2): 27-38.

15. Schumacher MA, Basbaum AI, Way WL. Opioid analgesics and antagonists. In: Katzung BG (ed). Basic and Clinical Pharmacology. 9th ed. The McGraw-Hill Companies, Boston, 2004:497-516.

16. Soares LG. Methadone for cancer pain: what have we learned from clinical studies? Am J Hosp Palliat Care 2005; 22(3): 223-7.

17. Vallerand AH. The use of long-acting opioids in chronic pain management. Nurs Clin North Am 2003; 38(3): 435-45.

18. Cherny NI, Foley KM. Current approaches to the management of cancer pain: a review. Ann Acad Med Singapore 1994; 23(2): 139-59.

19. Bruera E, Willey JS, Ewert-Flannagan PA, Cline MK, Kaur G, Shen L, Zhang T, Palmer JL. Pain intensity assessment by bedside nurses and palliative care consultants: a retrospective study. Support Care Cancer 2005;13(4):228-31.

20. Anderson KO, Richman SP, Hurley $\mathrm{J}$ et al. Cancer pain management among undeserved minority patients: perceived needs and barriers to optimal control. Cancer 2002; 94(8): 2295-304.

21. Miaskowski C, Dodd MJ, West $C$ et al. Pain reports by older hospice cancer patients and family caregivers: the role of cognitive functioning. Gerontologist 2002; 42(2): 507-14.

22. Levy MH, Samuel TA. Management of cancer pain. Semin Oncol 2005; 32(2): 179-93.

23. Cherny NI. The pharmacologic management of cancer pain. Oncology (Williston Park) 2004; 18(12): 1499-515.

24. McDonnell FJ, Sloan JW, Hamann SR. Advances in cancer pain management. Curr Oncol Rep 2000; 2(4): 351-7.

25. Mancini I, Body JJ. Treatment of cancer pain: the role of co-analgesics. Rev Med Brux 1998; 19(4): A319-22.

26. Morimoto M. Adjuvant analgesics in cancer pain: clinical pharmacology and efficacy. Nippon Rinsho 2001; 59(9): 180611.

27. McNicol E, Strassels SA, Goudas L, Lau J, Carr DB. NSAIDS or paracetamol, alone or combined with opioids for cancer pain. Cochrane Database Syst Rev 2005;(1): CD005180.

28. Dohi S. Non-opioid analgesics in cancer pain. Nippon Rinsho 2001; 59(9): 1800-5

29. McNicol E, Strassels SA, Goudas L, Lau J, Carr DB. Nonsteroidal anti-inflammatory drugs, alone or combined with opioids, for cancer pain: a systematic review. J Clin Oncol 2004; 22(10): 1975-92.

30. Eisenberg E, Berkey CS, Carr DB, Mosteller F, Chalmers TC. Efficacy and safety of nonsteroidal anti-inflammatory drugs for cancer pain: a meta-analysis. J Clin Oncol 1994; 12(12): 2756-65.

31. Hoskin PJ, Hanks GW. Opioid agonist-antagonist drugs in acute and chronic pain states. Drugs 1991; 41(3): 326-44.

32. Wiffen PJ, Edwards JE, Barden J, McQuay HJ. Oral morphine for cancer pain. Cochrane Database Syst Rev 2003; (4): CD003868.

33. Mancini I, Lossignol DA, Body JJ. Opioid switch to oral methadone in cancer pain. Curr Opin Oncol 2000; 12(4): 308-13.

34. Bruera E, Palmer JL, Bosnjak $S$ et al. Methadone versus morphine as a first-line strong opioids for cancer pain: a randomized, double-blind study. J Clin Oncol 2004; 22(1): 185-92.

35. Mercadante S, Casuccio A, Agnello A, Serretta R, Calderone L, Barresi L. Morphine versus methadone in the pain treatment of advanced-cancer patients followed up at home. J Clin Oncol 1998; 16(11): 3656-61.

36. Mercadante $S$, Bianchi $M$, Villari $P$ et al. Opioid plasma concentration during switching from morphine to methadone: preliminary data. Support Care Cancer 2003; 11(5): 326-31.

37. Mercadante S, Casuccio A, Calderone L. Rapid switching from morphine to methadone in cancer patients with poor response to morphine. J Clin Oncol 1999; 17(10): 3307-12.

38. Zeppetella G, Ribeiro MD. Opioids for the management of breakthrough (episodic) pain in cancer patients. Cochrane Database Syst Rev 2006; (1):CD004311.

39. Farrar JT, Cleary J, Rauck R, Busch M, Nordbrock E. Oral transmucosal fentanyl citrate: randomized, double-blinded, placebo-controlled trial for treatment of breakthrough pain in cancer patients. J Natl Cancer Inst 1998; 90(8): 611-6.

40. Portenoy RK, Payne R, Coluzzi P et al. Oral transmucosal fentanyl (OTFC) for the treatment of breakthrough pain in cancer patients: a controlled dose titration study. Pain 1999; 79(2-3): 303-12.

41. Payne R, Coluzzi $P$, Hart $L$ et al. Long-term safety of oral transmucosal fentanyl citrate for breakthrough cancer pain. $J$ Pain Symptom Manage 2001; 22(1): 575-83.

42. Sittl R, Griessinger N, Likar R. Analgesic efficacy and tolerability of transdermal buprenorphine in patients with inadequately controlled chronic pain related to cancer and other disorders: a multicenter, randomized, double-blind, placebo-controlled trial. Clin Ther 2003; 25(1): 150-68.

43. Likar R, Kayser H, Sittl R. Long term management of chronic pain with transdermal buprenorphine: a multicenter, openlabel, follow-up study in patients from three short-term clinical trials. Clin Ther 2006; 28(6): 943-52.

44. Bono AV, Cuffari S. Effectiveness and tolerance of tramadol in cancer pain. A comparative study with respect to buprenorphine. Drugs 1997; 53 Suppl 2: 40-9.

45. Dayer P, Desmeules J, Collart L. Pharmacology of tramadol. Drugs 1997; 53 Suppl 2: 18-24. Drugs 1997; 53 Suppl 2: 18-24.

46. Keskinbora K, Aydinli I. An atypical opioids analgesic: tramadol. Agri 2006; 18(1): 5-19.

47. Grond S, Sablotzki A. Clinical pharmacology of tramadol. Clin Pharmacokinet 2004; 43(13): 879-923.

48. Ripamonti C, Dickerson ED. Strategies for the treatment of cancer pain in the new millennium. Drugs 2001; 61(7): 95577. 